\title{
Tissue-specific turnover rates of the nitrogen stable isotope as functions of time and growth in a cyprinid fish
}

\author{
Georgina M. A. Busst · J. Robert Britton (1)
}

Received: 15 March 2017/Revised: 15 June 2017/ Accepted: 19 June 2017/Published online: 30 June 2017

(C) The Author(s) 2017. This article is an open access publication

\begin{abstract}
Ecological applications of stable isotope data require knowledge on the isotopic turnover rate of tissues, usually described as the isotopic half-life in days $\left(T_{0.5}\right)$ or the change in mass $\left(G_{0.5}\right)$. Ecological studies increasingly analyse tissues collected nondestructively, such as fish fin and scales, but there is limited knowledge on their turnover rates. Determining turnover rates in situ is challenging, with ex situ approaches preferred. Correspondingly, $T_{0.5}$ and $G_{0.5}$ of the nitrogen stable isotope $\left(\delta^{15} \mathrm{~N}\right)$ were determined for juvenile barbel Barbus barbus $(5.5 \pm 0.6 \mathrm{~g}$ starting weight) using a diet-switch experiment. $\delta^{15} \mathrm{~N}$ data from muscle, fin and scales were taken during a 125 day post diet-switch period. Whilst isotopic equilibrium was not reached in the 125 days, the $\delta^{15} \mathrm{~N}$ values did approach those of the new diet. The fastest turnover rates were in more metabolically active tissues, from muscle (highest) to scales (lowest). Turnover rates were relatively slow; $T_{0.5}$ was 84 (muscle) to 145 (scale) days; $G_{0.5}$ was $1.39 \times$ body
\end{abstract}

Handling editor: Michael Power

Electronic supplementary material The online version of this article (doi:10.1007/s10750-017-3276-2) contains supplementary material, which is available to authorised users.

G. M. A. Busst · J. R. Britton ( $\square)$

Department of Life and Environmental Sciences, Faculty

of Science and Technology, Bournemouth University,

Poole BH12 5BB, UK

e-mail: rbritton@bournemouth.ac.uk mass (muscle) to $2.0 \times$ body mass (scales), with this potentially relating to the slow growth of the experimental fish. These turnover estimates across the different tissues emphasise the importance of estimating half-lives for focal taxa at species and tissue levels for ecological studies.

Keywords Isotopic equilibrium $\cdot$ Fin tissue $\cdot$ Scale $\cdot$ Stable isotope

\section{Introduction}

Knowledge on the stable isotope turnover rates of tissues of a consumer species is fundamental for the correct interpretation of their isotopic ecology (Boecklen et al., 2011). Stable isotope turnover rates tend to be expressed as half-lives, i.e. the time for stable isotope values to reach $50 \%$ equilibrium with a new diet (Vander Zanden et al., 2015). Estimates of isotopic turnover rates are important for understanding how, for example, ontogenetic dietary shifts affect stable isotope data (e.g. Buchheister \& Latour, 2010; Hertz et al., 2015), and for incorporating into the design of manipulative field studies and mesocosm experiments where the duration of the study could be confounded if they are not of sufficient length for isotopic equilibrium to be reached (Jackson et al., 2013; Tran et al., 2015). Consumer tissues tend to be considered at equilibrium with their diet after $4-5$ halflives (Hobson \& Clark, 1992). 
Increasingly, the sampling of tissues for stable isotope analysis utilises the non-invasive or non-destructive sampling of tissues, such as using fin tissue and scales rather than dorsal muscle for fishes (Busst et al., 2015; Busst \& Britton, 2016; Vašek et al., 2017). Knowledge on the turnover rates of these tissues is often missing, leading to problems in their application to ecological studies (Busst \& Britton, 2016). Moreover, the determination of the turnover rates of wild consumers can be problematic, as they tend to assimilate a range of prey items that vary temporally and spatially in isotopic content (Perga \& Gerdeaux, 2005). Consumer species are also unlikely to feed on the same proportions of prey items on a daily basis and consumer isotopic turnover rates are also influenced by a number of other factors, including temperature fluctuations and life-history events (Bearhop et al., 2002; Bosley et al., 2002; Witting et al., 2004). Turnover rates also differ between fish species and between different tissues of individual species (e.g. McIntyre \& Flecker, 2006; Church et al., 2009; Carleton \& Del Rio, 2010). Rather than relying on data collected in the wild, an alternative approach is the use of experimental diet-switch studies completed in controlled conditions (Heady \& Moore, 2013; Xia et al., 2013a, b; Busst \& Britton, 2016). In these studies, diet tends to be fixed so that the food items have relatively consistent stable isotope values that should provide more reliable turnover estimates in the tissues (Logan et al., 2006). These approaches should also provide enhanced understandings of the mechanisms involved in isotopic replacement (Buchheister \& Latour, 2010; Heady \& Moore, 2013). The data generated also favour the testing of different models to determine the best-fitting model that provides the best estimate of the turnover rate, and enable the relative contributions of growth and metabolism to turnover to be estimated (Fry \& Arnold, 1982; Hobson \& Clark, 1992; Hesslein et al., 1993).

Estimating the relative contributions of growth and metabolism to isotopic turnover rates is important, as both play important roles in the isotopic replacement of tissues following a diet-switch (Xia et al., 2013a, b). Growth rate represents the synthesis of new tissue from the new diet, whereas the metabolic rate represents the balanced rate of breakdown of old tissue, synthesised during feeding on a previous diet, and the re-synthesis of tissue components made from the new diet (Hesslein et al., 1993). Thus, with known growth rates, the proportional contributions of metabolism and growth to stable isotopic turnover are estimated from non-linear regression of the isotopic turnover trajectories (Buchheister \& Latour, 2010). The change in isotopic content within the tissues can, therefore, be modelled as a function of time or growth using a range of different models (Fry \& Arnold, 1982; Hobson \& Clark, 1992; Hesslein et al., 1993).

Correspondingly, the aim of this study was to determine for ${ }^{15} \mathrm{~N}$ the turnover rate and the respective contributions of metabolism and growth within the tissues of a model freshwater fish using an experimental, diet-switch approach. Using three tissues (dorsal muscle, fin and scale tissue) of the omnivorous European barbel Barbus barbus (Linnaeus, 1758) of the Cyprinidae family, objectives were to: (i) determine the turnover rates of ${ }^{15} \mathrm{~N}$ in dorsal muscle, fin and scales of $B$. barbus through the application of five time- and growth-based models; (ii) quantify the proportional contributions of metabolism and growth to the turnover rates of ${ }^{15} \mathrm{~N}$ in each tissue; and (iii) identify the best-fitting time- and growth-based models for estimating tissue-specific ${ }^{15} \mathrm{~N}$ turnover rates.

A recent study revealed considerable differences in the $\delta^{15} \mathrm{~N}$ fractionation of $B$. barbus according to the extent of either fishmeal or plant material in their diet (Busst \& Britton, 2016). Thus, their use here provides a strong model to determine turnover rates based on these food items. Barbus barbus is also an important riverine species in many European rivers (Britton \& Pegg, 2011), being a benthic foraging species that often specialises in feeding on baits introduced by anglers (Gutmann Roberts et al., 2017). They are also invasive in a number of European rivers, with concern over the interactions of their populations with indigenous fishes (Bašić et al., 2016). Consequently, knowledge on their nitrogen stable isotope turnover rate has importance for ecological studies on their trophic position and impacts, with many of these studies likely to be reliant on the non-destructive sampling of scales and fin tissue due to the value of their populations to recreational angling (Britton \& Pegg, 2011).

\section{Materials and methods}

\section{Experimental design}

The experiment utilised 36 juvenile $B$. barbus that originated from pond aquaculture where they had been 
reared in outdoor ponds and fed a mixture of natural food resources supplemented with formulated feeds. Their initial fork lengths and weights ranged between 75 and $85 \mathrm{~mm}$ and 4 and $7 \mathrm{~g}$, respectively. Following their transfer to the laboratory, they were acclimated to conditions for 10 days before being measured and tagged with $12 \mathrm{~mm}$ passive integrated transponder (PIT) tags to enable their subsequent individual identification. The fish were then measured (fork length, nearest $\mathrm{mm}$ ) and weighed (to $0.01 \mathrm{~g}$ ). The experimental design then incorporated two feeding periods. The first was on a set formulated diet, to provide all fish with similar isotopic values, and lasted 125 days; the second immediately followed this and consisted of an alternative formulated feed for a further 125 days during which the changes in the isotopic values of the fish were measured. These timescales were used because 125 days was assumed to have provided at least four isotopic half-lives according to the starting mass of individual fish $(<10 \mathrm{~g})$ and according to values in literature (Hobson \& Clark, 1992; Thomas \& Crowther, 2015). Consequently, the fish should have been close to isotopic equilibrium at the end of each of these periods.

After their tagging and measurement, the fish were transferred to 451 tanks at $20{ }^{\circ} \mathrm{C}$ where they were held in groups of 6 and were fed a 'control' diet ad libitum for 125 days. This feed consisted of crushed pelletized fishmeal (45\% protein, $10 \%$ fat, $1.4 \%$ crude fibre and $5.8 \%$ ash) that had a mean $\delta^{15} \mathrm{~N}$ value of $9.34 \pm 0.05 \% \quad(n=5)$. At the end of the first 125 day feeding period, the fish were removed from their tanks, re-measured and weighed, and separated into three groups. The first two groups each comprised of $6 \mathrm{~B}$. barbus. One of these groups was immediately euthanized with an overdose of anaesthetic (MS-222) and used to provide stable isotope data on the tissues of the fish at the start of the second feeding period. The second of these groups was used as a 'control' group of fish kept in a separate 451 tank and fed the control diet for the entirety of the second 125 day feeding period. The third group of fish comprised of 24 fish that were used for the diet-switch experiment and were held in 451 tanks in groups of 6. The new food source, hereafter referred to as the 'experimental' diet, was a plant based feed, pelletized 'wheatgerm' (20\% protein, $6 \%$ fat (as oil), $2.5 \%$ crude fibre and $2.5 \%$ ash), with a mean $\delta^{15} \mathrm{~N}$ value of $3.28 \pm 0.02 \%$ o $(n=5)$. For the diet-switch fish, 6 fish were removed and euthanized on day 50, 75, 100 and 125 respectively (anaesthetic overdose, MS-222), with these fish selected randomly from tanks. Their feeding was ad libitum, with temperature maintained between 19 and $20{ }^{\circ} \mathrm{C}$ on a 16:8 h light:dark cycle, with water quality maintained on a flow through, recirculating system. Environmental enrichment in the tanks was identical, comprising of artificial plants and plastic pipes of $65 \mathrm{~mm}$ diameter and $120 \mathrm{~mm}$ length for refugia.

Following euthanasia of the fish at each sampling time point, they were re-measured and weighed, with a sample of white dorsal muscle tissue excised from above the lateral line and below the dorsal fin, with pelvic fin clips sampled (taken from the tip of the fin; Hayden et al., 2015) and then scales $(n=5-10)$ also removed from the area above where the muscle sample was taken. Note that on Day 100, one of the fish was detected as not having increased in length or weight and so was omitted from subsequent analyses $(n=5)$. All samples were then rinsed with distilled water, with scales also cleaned to ensure all mucus and skin was removed. All scales used in analyses were checked to determine whether they were regenerated scales and, if so, were not used. All samples were then oven dried at $60{ }^{\circ} \mathrm{C}$ to constant mass (approximately $1 \mathrm{mg}$; for scales this comprised of up to 10 scales per fish) before their analysis for $\delta^{15} \mathrm{~N}(\%)$ at the Cornell University Stable Isotope Laboratory, New York, USA. In the analysis of $\delta^{15} \mathrm{~N}$, overall standard deviation was $0.11 \%$ and analytical precision of the sample runs was $0.42 \%$. It should be noted that although $\delta^{13} \mathrm{C}$ was also measured in the samples, the differences in their values across the experimental period were too low to enable measurement of their turnover rate. This was due to the $\delta^{13} \mathrm{C}$ of the two diets being too similar.

Time-based modelling of the nitrogen stable isotope turnover rate

The time-based model estimated the isotope turnover rates in each of the different $B$. barbus tissues through modelling changes in $\delta^{15} \mathrm{~N}$ as an exponential function of time following the diet-switch, as described by Hobson and Clark (1992):

$\delta t=(\delta i-\delta f) e^{c t}+\delta f$

where $\delta t$ is the $\delta^{15} \mathrm{~N}$ value of fish tissue at experimental time $t, \delta f$ is the expected isotopic value for $B$. 
barbus in equilibrium with the new diet, $\delta i$ is the initial $\delta^{15} \mathrm{~N}$ prior to the diet-switch, and $c$ is the turnover constant. $\delta f$ was estimated using non-linear regression. The mean $\delta^{15} \mathrm{~N}$ of the 6 fish collected before the dietswitch were used as the estimate of $\delta i$ in the model; $c$ was derived by fitting the exponential model in (1) to match the observed isotopic data, i.e. using the experimental time $(t)$ as the independent variable and the corresponding $\delta^{15} \mathrm{~N}$ values of fish at time $t(\delta t)$ as the dependent variable. The time period needed to achieve a $50 \%$ turnover (half-life, $T_{0.5}$ ) of $\delta^{15} \mathrm{~N}$ was calculated as (Hobson \& Clark, 1992):

$T_{0.5}=\ln (0.5) / c$

To allow the relative contributions of growth and metabolism to stable isotope turnover to be separated, a second time-based model was used, as described by Hesslein et al. (1993):

$\delta t=\delta f+(\delta i-\delta f) \mathrm{e}^{-(k+m) t}$

where $\delta t, t, \delta f$ and $\delta i$ are as previously defined in Eq. 1 . $m$ was the metabolic turnover constant derived by fitting the exponential model in Eq. 3 to match the observed isotopic data, i.e. using the experimental time $(t)$ as the independent variable, and the corresponding $\delta^{15} \mathrm{~N}$ values of fish at time $t(\delta t)$ as the dependent variable. The growth rate constant $k$ was represented by the specific growth rate; this was determined for each individual fish from (Sun et al., 2012):

$k=\ln \left(W_{\mathrm{f}} / W_{\mathrm{i}}\right) / t$

where $W_{\mathrm{i}}$ is the initial weight of B. barbus on Day 0, and $W_{\mathrm{f}}$ is the final weight when sampled at time $t$. Any turnover of $\delta^{15} \mathrm{~N}$ in excess of growth was attributable to metabolic tissue replacement $(m)$. Expected $\delta^{15} \mathrm{~N}$ changes due to growth alone was calculated using Eq. 3, where $m$ was set to 0 (Hesslein et al., 1993). The relative contributions of growth $(k)$ and metabolism $(\mathrm{m})$ were calculated as the ratio of each parameter to the sum of the two parameters $(k+m)$. This calculation yielded the contributing proportions of growth $\left(P_{\mathrm{g}}\right)$ and metabolism $\left(P_{\mathrm{m}}\right)$ to the turnover of $\delta^{15} \mathrm{~N}$. The half-life $\left(T_{0.5}\right)$ of tissue turnover of $\delta^{15} \mathrm{~N}$ was calculated using (Tieszen et al., 1983):

$T_{0.5}=-\ln (1-0.5) /(k+m)$
Growth-based modelling of nitrogen stable isotope turnover rate

The changes in $\delta^{15} \mathrm{~N}$ caused by the diet shift were then modelled as a function of the subsequent increase in mass. This was initially done by adjusting the timebased equation of Hobson \& Clark (1992), Eq. 1, by substituting $t$ for the increase in mass from Day $0(\mathrm{~m})$. The growth-based model was thus represented by:

$\delta m=(\delta i-\delta f) e^{c m}+\delta f$

where $t, \delta f, \delta i$, and $c$ are as previously defined in Eq. 1 and $\delta m$ is $\delta^{15} \mathrm{~N}$ at mass increase $m$. The increase in mass required to achieve a 50\% turnover (half-life, $G_{0.5}$ ) of $\delta^{15} \mathrm{~N}$ was calculated as (Hobson \& Clark, 1992):

$G_{0.5}=\ln (0.5) / m$

Similar to the time-based modelling, a second growth-based model was then also applied to enable the relative contributions of growth and metabolism to turnover to be separated. Changes in $\delta^{15} \mathrm{~N}$ were modelled as a function of relative growth after the diet-switch. The growth-based model was represented by (Fry \& Arnold, 1982):

$\delta W_{\mathrm{R}}=\delta f+(\delta i-\delta f) W_{\mathrm{R}}^{c}$

where $\delta i$ and $\delta f$ are as previously defined in Eq. 1. The relative increase in weight of $B$. barbus $\left(W_{\mathrm{R}}\right)$ was calculated as the final wet weight divided by the initial wet weight, and the variable $\delta W_{R}$ was the measured isotopic value for a fish given its increase in weight; $c$ was the turnover rate constant and was derived by fitting the exponential model in Eq. 8 to match the observed isotopic data, i.e. using the relative mass increase $W_{R}$ as the independent variable, and the $\delta^{15} \mathrm{~N}$ values corresponding to the $W_{\mathrm{R}}\left(\delta W_{\mathrm{R}}\right)$ as the dependent variable. In the growth-based model, if $c=-1$, growth was entirely responsible for the isotopic turnover, whereas if $c<-1$, metabolism was contributing to turnover, with more negative values representing greater contributions by metabolism. Note that in Eq. 8, it was the only case where $c$ had to be constrained in this manner; elsewhere, $c$ was able to be $>-1$. The amount of relative growth needed to achieve a $50 \%$ turnover (half-life, $G_{0.5}$ ) of $\delta^{15} \mathrm{~N}$ was calculated as (Buchheister \& Latour, 2010): 
$G_{0.5}=e^{\ln (1-0.5) / c}$

where the growth-based half-life $\left(G_{0.5}\right)$ represented the relative amount of growth needed for a $50 \%$ conversion between the initial and final stable isotope values. Hence, the half-lives estimated with this growth-based model were expressed as an $x$-fold mass increase. The fractions of new tissue derived from growth $\left(D_{\mathrm{g}}\right)$ and from metabolism $\left(D_{\mathrm{m}}\right)$ were calculated at the midpoint between the old and new isotopic values (Witting et al., 2004):

$D_{\mathrm{g}}=2\left(G_{0.5}-1\right) / G_{0.5}$

$D_{\mathrm{m}}=\left(2-G_{0.5}\right) / G_{0.5}$

\section{Model fitting and selection}

To determine the best-fitting models for the stable isotope data across both the growth- and time-based methods, five models (A-E) were assessed using an information-theoretic approach based on the isotopic equilibrium models outlined in Eqs. 1-5 (time based) and 6-11 (growth based) (Fry \& Arnold, 1982; Hobson \& Clark, 1992; Hesslein et al., 1993; Table 1). The models either estimated $\delta f$ (the value of the stable isotope when in equilibrium with the diet) via non-linear regression (Models A, C, E) or used the mean $\delta^{15} \mathrm{~N}$ data of the experimental fish on Day 125 of the second experimental period (Models B, D) (Table 1). Models were parameterised to either include or exclude a metabolic constant to turnover to examine how metabolism affected the turnover rates of the tissues (i.e. for Eqs. 3 and 8, $m$ was set to 0 and $c$ was set to -1 , respectively) (Table 1 ).

These model formulations were fitted to each isotope-tissue combination and were assessed separately for the growth- and time-based methods. To then evaluate the best model parameterisation, i.e. the model providing the best estimate of $T_{0.5}$ and $G_{0.5}$, Akaike's information criterion (AIC) was calculated for each model, with application of a correction for small sample sizes (AICc). This was performed using the AICcmodavg package in the $\mathrm{R}$ computing programme ( $\mathrm{R}$ Development Core Team, 2014; Mazerolle, 2016). AICc differences ( $\triangle \mathrm{AICc}$ ) among the five models were calculated as:

$\Delta \mathrm{AICc}=\mathrm{AIC} i-\mathrm{AICmin}$

where $\mathrm{AIC} i$ is the AICc of model $i$, and AICmin is the lowest AICc of the competing models. The model with the most empirical support generated $\triangle \mathrm{AICc}=0$. Burnham and Anderson (2002) suggest that $\triangle \mathrm{AICc}$ values from 0 to 2 indicate substantial support for the model, $\triangle$ AICc values from 4 to 7 suggested considerably less support, and $\Delta \mathrm{AICc}$ values $>10$ indicated minimal support for that model.

\section{Statistical analyses}

Differences in the isotopic ratios between the sampling time points in the experiment and between the three types of tissue, i.e. muscle, fin and scales, were analysed using generalised linear models (GLM), with either the sampling time points or tissue types as independent variables and $\delta^{15} \mathrm{~N}$ as the dependent

Table 1 Overview of the turnover models compared in model selection

\begin{tabular}{lll}
\hline Model & Equations & Comments \\
\hline A & $\begin{array}{l}\text { Time based: } 1,2 \\
\text { Growth based: } 6,7\end{array}$ & Specific turnover parameter estimated; $\delta f$ estimated \\
B & $\begin{array}{l}\text { Time based: } 1,2 \\
\text { Growth based: } 6,7\end{array}$ & Specific turnover parameter estimated; $\delta f$ derived from experimental fish \\
C & $\begin{array}{l}\text { Time based: } 1-5 \\
\text { Growth based: } 6-11\end{array}$ & As Model A, but with contributions of growth and metabolism to turnover now also incorporated \\
D & $\begin{array}{l}\text { Time based: } 1-5 \\
\text { Growth based: } 6-1\end{array}$ & As Model B, but with contributions of growth and metabolism to turnover now also incorporated \\
E & Time based: $1-5$ & As Model C, but with $m=0$ and $\mathrm{c}=-1$ \\
& Growth based: $6-11$ &
\end{tabular}

Fry and Arnold (1982), Hobson and Clark (1992), Hesslein et al. (1993) 
variable. Differences in the dependent variables according to the independent variables and their significance were determined by pairwise comparisons with Bonferroni adjustments for multiple comparisons.

\section{Results}

Fish growth and $\delta^{15} \mathrm{~N}$

All of the $B$. barbus individuals increased in length and mass over the first 125 day control feeding period, with mean fork lengths and weights increasing from $79.6 \pm 2.8$ to $89.3 \pm 4.6 \mathrm{~mm}$ and $5.5 \pm 0.6$ to $8.1 \pm 1.3 \mathrm{~g}$, respectively. Following the diet-switch, all $B$. barbus individuals in the control and experimental groups also increased in length and mass during the second 125 day period, with their increments varying according to the timing of the removal of the fish from the tanks (Table 2).

Values of muscle $\delta^{15} \mathrm{~N}$ were significantly related to those of the other analysed tissues (muscle-fin: $R^{2}=0.85 ; \quad F_{1,27}=11.71 ; P<0.01 ;$ muscle-scale: $R^{2}=0.91 ; \quad F_{1,27}=12.55 ; \quad P<0.01 ;$ Fig. 1$)$. The muscle conversion equation for fin tissue $(F)$ was $1.099 F-0.605$ and for scales $(S)$ was $1.269 S-2.106$. Across the experiment, there were decreases in $\delta^{15} \mathrm{~N}$ at each sampling time point (Fig. 2). The GLM testing the differences in $\delta^{15} \mathrm{~N}$ over time was significant (Wald $\chi^{2}=801.02, P<0.01$ ). Pairwise comparisons revealed that $\delta^{15} \mathrm{~N}$ of the $6 B$. barbus euthanized on Day 0 of the diet-switch experiment with the control group of $6 \mathrm{~B}$. barbus were not significantly different to the control group during the second period $(P>0.05$; Table 3$)$. In the

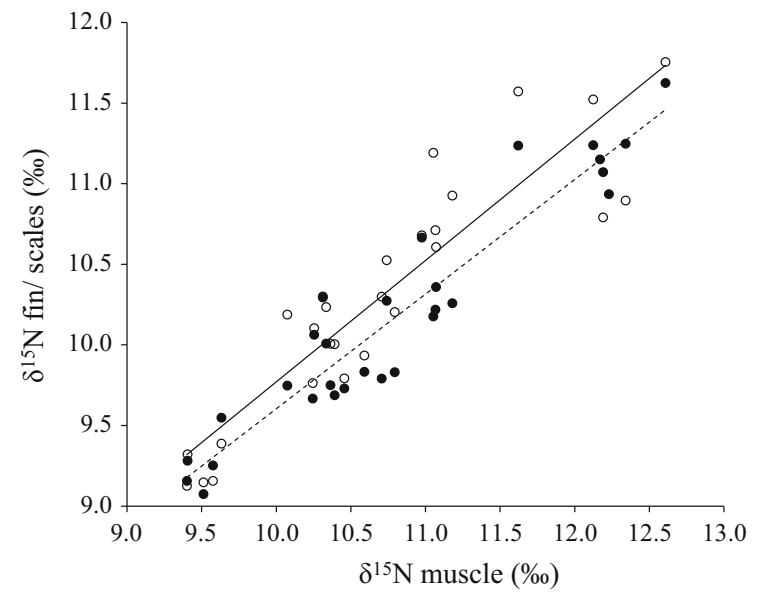

Fig. 1 Linear relationships $\delta^{15} \mathrm{~N}$ of muscle of experimental fishes versus fin tissue (clear circles, solid line) and scales (filled circles, dashed line)

second feeding period, the euthanized fish at each sampling time point revealed significant shifts in $\delta^{15} \mathrm{~N}$ when these data were compared to the fish at Day 0 $(P<0.05)$. The exception was fin tissue, where a significant shift was not apparent until Day 75 $(P<0.05)$. At each sampling time point, muscle had the highest $\delta^{15} \mathrm{~N}$ values and scales the lowest (Fig. 2).

\section{Turnover estimates}

The best-fitting models for the time-based models were Model $\mathrm{C}$ for muscle and fin tissue, and $\mathrm{E}$ for scales (Table 3; Supplementary Table S1). These all suggested that isotopic equilibrium had not been reached in the second 125 day period (Table 3; Fig. 3). Muscle had the shortest turnover time with a half-life of 84 days (95\% turnover: 371 days), then fin

Table 2 Sample size, and mean length and mass of Barbus barbus in the experimental and control groups at each sampling time point

\begin{tabular}{llcrl}
\hline Time point & $n$ & Fork length $(\mathrm{mm})$ & Weight $(\mathrm{g})$ & Weight increment $(\mathrm{g})$ \\
\hline Day 0 & 6 & $90.2 \pm 5.3$ & $7.7 \pm 1.2$ & $2.3 \pm 0.5$ \\
Day 50 & 6 & $102.5 \pm 3.0$ & $12.2 \pm 0.7$ & $3.6 \pm 0.8$ \\
Day 75 & 6 & $103.2 \pm 3.4$ & $11.9 \pm 1.1$ & $4.1 \pm 1.4$ \\
Day 100 & 5 & $111.8 \pm 3.5$ & $11.8 \pm 1.1$ & $8.7 \pm 1.2$ \\
Day 125 & 6 & $139.7 \pm 7.2$ & $30.3 \pm 5.5$ & $8.5 \pm 1.1$ \\
Control Day 125 & 6 & & $16.6 \pm 1.5$ & \\
\hline
\end{tabular}

Errors around the means represent $95 \%$ confidence limits 


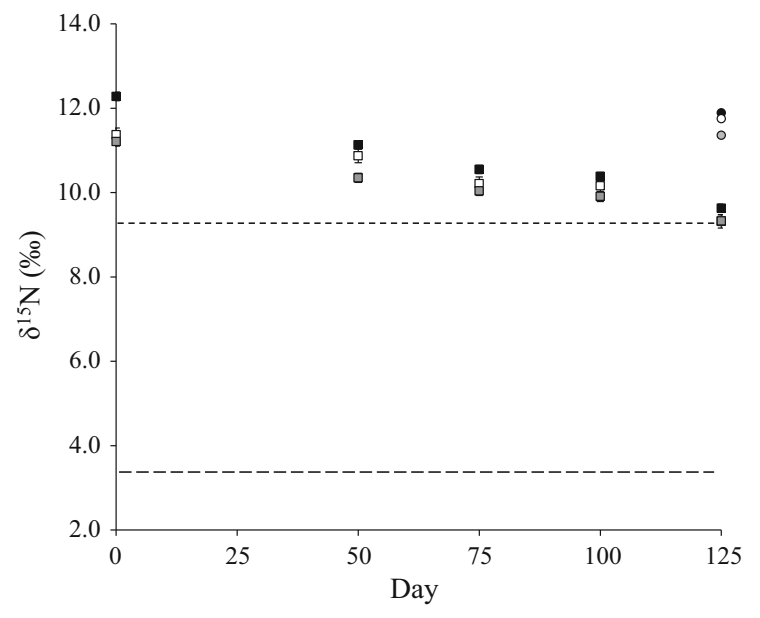

Fig. 2 Mean stable isotope $\left(\delta^{15} \mathrm{~N}\right)$ values of the control and experimental diets and tissues of $B$. barbus fish in the experimental and control groups at each sampling time point. Errors around the means represent standard errors. Black circle control fish, muscle; clear circle control fish, fin tissue; grey circle control fish, scales; black square experimental fish, muscle; clear square experimental fish, fin tissue; grey square experimental fish, scales. Long dashed line mean $\delta^{15} \mathrm{~N}$ of experimental diet; short dashed line mean $\delta^{15} \mathrm{~N}$ of control diet

at 95 days (95\% turnover: 417 days), and then scales at 145 days (95\% turnover: 638 days) (Table 3 ; Fig. 3).

Similar to the time-based models, predicted values of $\delta f$ in growth-based models also suggested equilibrium was not reached in the 125 day period (Table 3;

Table 3 Best-fitting models for (1) time-based models and (2) growth-based models for ${ }^{15} \mathrm{~N}$ turnover in muscle, fin and scale tissues of Barbus barbus, where $c$, turnover rate constant; $m$, metabolic constant; $k$, growth constant; $P m$, relative contributions of metabolism to turnover; $P g$, relative contributions of
Fig. 4). The best-fitting models for the growth-based models were Model $\mathrm{C}$ for muscle, and $\mathrm{E}$ for fin tissue and scales (Table 3; Supplementary Table S2). Muscle had the shortest turnover rate with a half-life of $1.39 \times \mathrm{BM}(95 \%$ turnover: $6.1 \times \mathrm{BM})$, with both fin and scales at $2.0 \times \mathrm{BM}(95 \%$ turnover: $10 \times \mathrm{BM})$ (Table 3; Fig. 4).

\section{Discussion}

The experiment successfully determined the isotopic half-lives and, by extension, the time and increase in mass to isotopic equilibrium of these juvenile $B$. barbus. In doing so, the experiment indicated the validity of using fin tissue and scales as non-lethal alternatives to dorsal muscles when isotopic studies are completed on fishes. In the experiment, the stable isotope data reflected and approached those of their new diet at the end of second feeding period, although predictions were that isotopic equilibrium had not been reached. Predicting the turnover processes using a range of turnover models (Buchheister \& Latour, 2010; Xia et al., 2013b) revealed that in the best-fitting models, muscle had the shortest turnover time, followed by fin and then scales.

This apparent hierarchy in the turnover rates of fish muscle, fin and scale tissue was a contrast to Matley et al. (2016) who revealed in an adult coral reef fish

\begin{tabular}{cccccccccc}
\hline Model & Tissue & $M$ & $R^{2}$ & $k+m$ & $P_{\mathrm{m}}$ & $P_{\mathrm{g}}$ & $\delta f(\% \mathrm{o})$ & $T_{0.5}$ & $\Delta$ AICc \\
\hline
\end{tabular}

(1) Time-based models

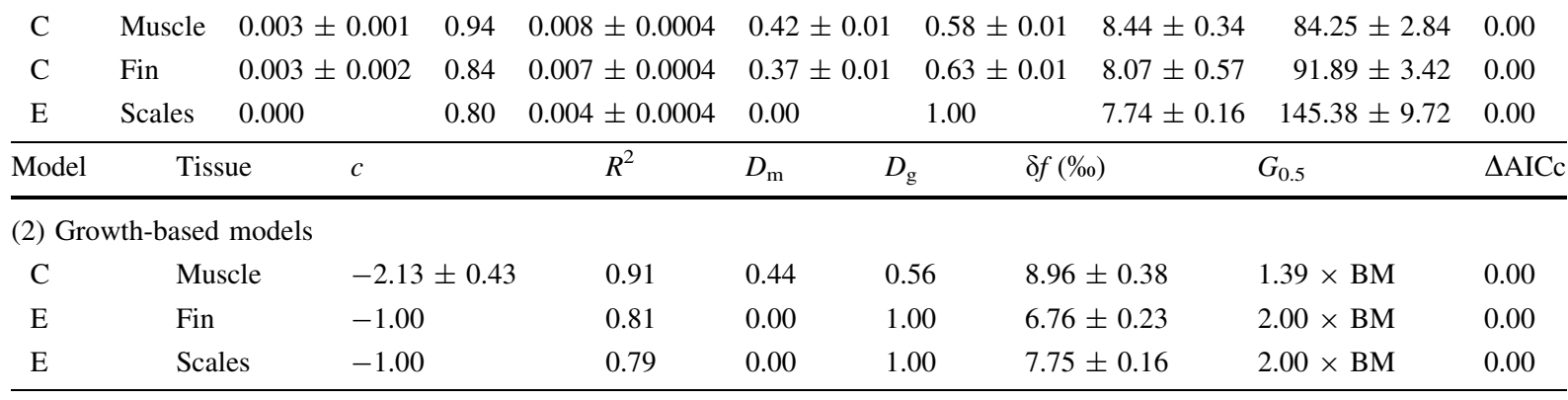

Errors around the means represent standard errors. Growth-based half-lives of model E are expressed as an $x$-fold increase in body mass $(x \mathrm{BM})$ 

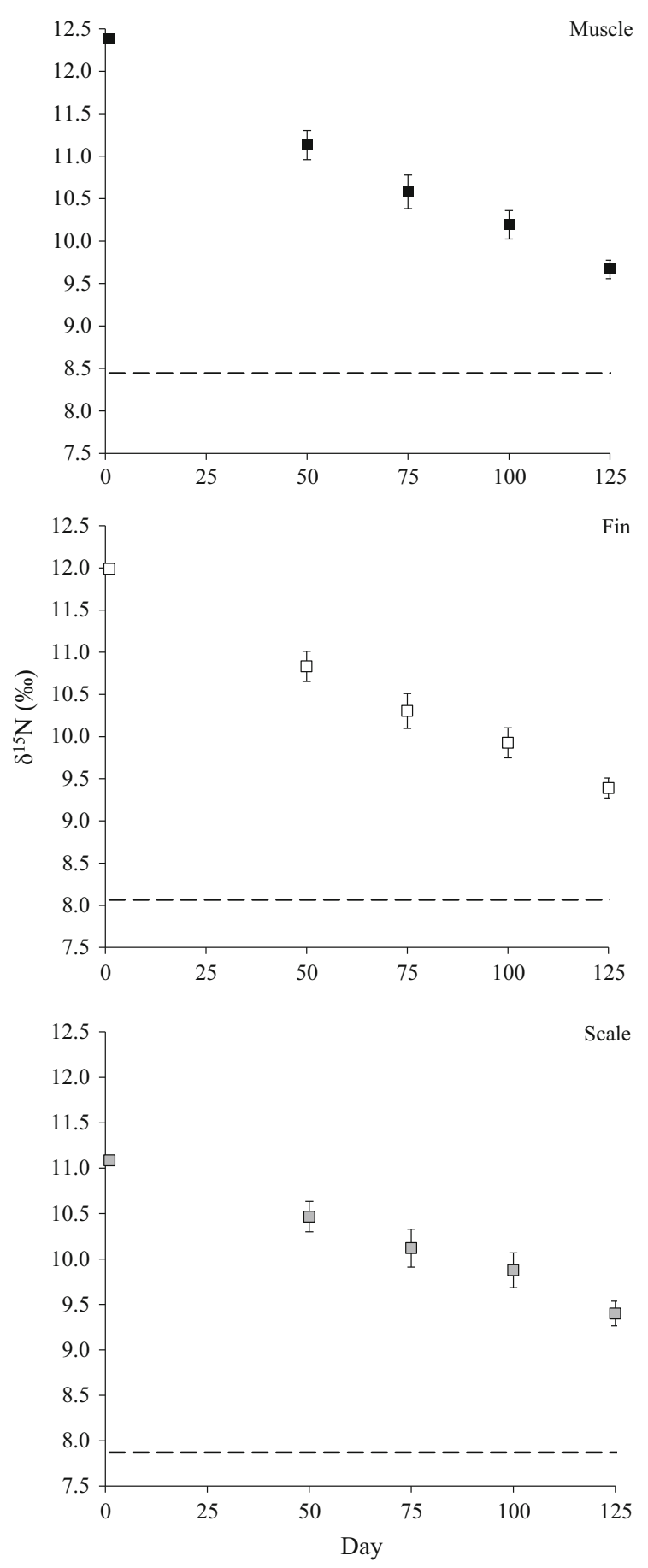

Fig. 3 Changes in Barbus barbus $\delta^{15} \mathrm{~N}$ as a function of time and tissue type according to the best-fitting model ( $c f$. Table 3 ). Black square muscle; clear square fin tissue; grey square scales. The horizontal dashed lines represent the expected final isotopic values of the tissues in equilibrium with experimental feed $(\delta f)$; error bars represent standard deviations
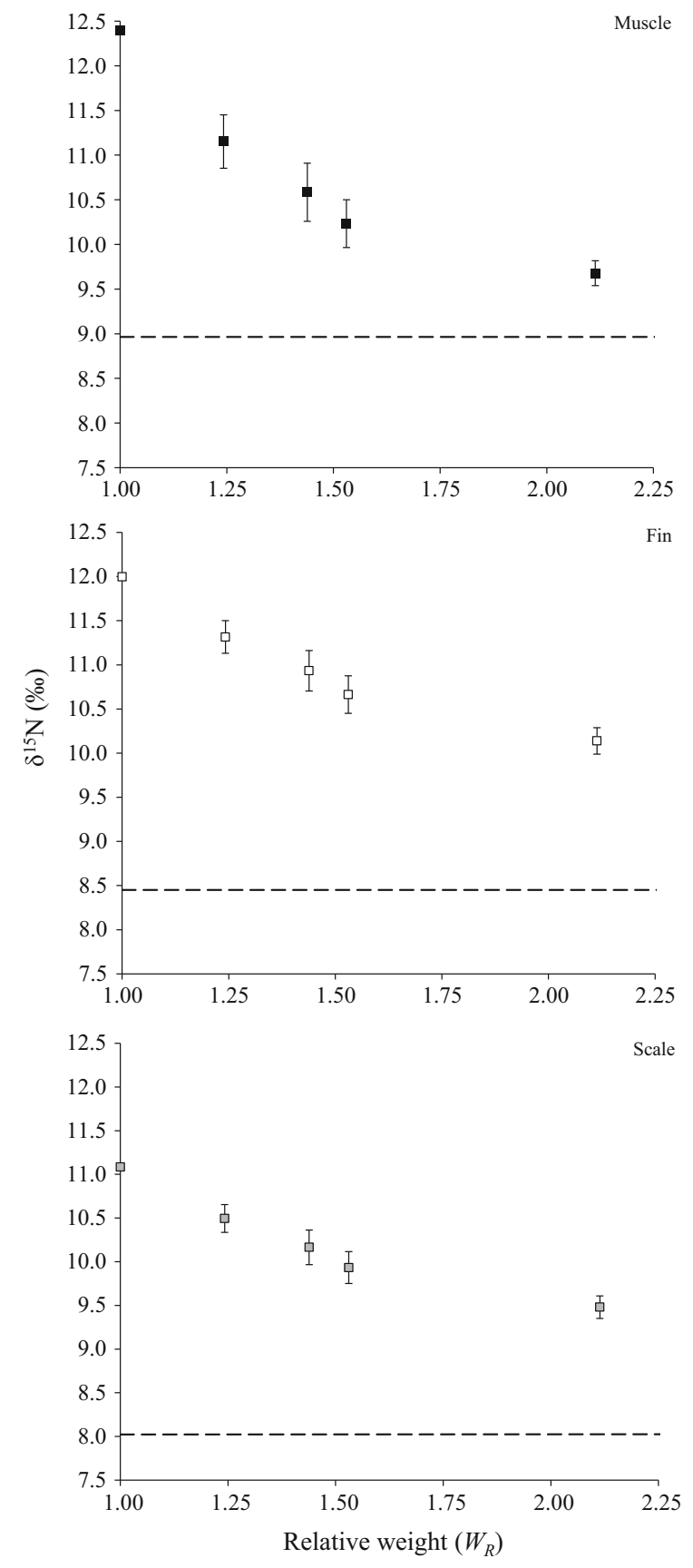

Fig. 4 Changes in Barbus barbus $\delta^{15} \mathrm{~N}$ as a function of growth and tissue type according to the best-fitting model ( $c f$. Table 3). Black square muscle; clear square fin tissue; grey square scales. The horizontal dashed lines represent the expected final isotopic values of the tissues in equilibrium with experimental feed $(\delta f)$; error bars represent standard deviations 
Plectropomus leopardus (Lacepède, 1802) muscle had a relatively long turnover rate compared with fin tissue. Other studies have, however, revealed that considerable differences in turnover rates can be apparent between fish tissues (Buchheister \& Latour, 2010; Xia et al., 2013b), although their differences are often only minor (Hesslein et al., 1993; Sweeting et al., 2005; McIntyre \& Flecker, 2006). Thus, tissue turnover differentiation, as well as the relative ordering of turnover rates among tissues, appears to be speciesspecific. For example, Heady and Moore (2013) calculated half-lives for muscle, fin and scales in rainbow trout Oncorhynchus mykiss (Walbaum, 1792) and found fin had the fastest isotopic half-life (13 days), followed by muscle (39 days) and scales (40 days). Whilst these $O$. mykiss turnover estimates are shorter than those produced here, the authors recognised that their turnover rates were fast, approximately $71 \%$ faster for muscle than previous estimates for $O$. mykiss from an isotope diet-switch study (Church et al., 2009). Buchheister and Latour (2010) studied summer flounder Paralichthys dentatus (Linnaeus, 1766) liver, blood and muscle tissue and found muscle had the slowest half-life (85 days). For grass carp Ctenopharyngodon idellus (Valenciennes, 1844), the estimated ${ }^{15} \mathrm{~N}$ half-life of muscle was 68 days (Xia et al., 2013b). Where differences between tissue turnover rates are detected in fishes, they generally follow the pattern that more metabolically active tissues show faster stable isotope turnover rates (Tieszen et al., 1983). Indeed, analysis of blood and blood plasma tends to result in faster turnover rates compared to the tissues used here (Thomas \& Crowther, 2015). The use of fish mucus has also been discussed as providing information on short-term diet patterns and changes due to low turnover rates (Church et al., 2009), with the advantage of it potentially being able to be collected non-destructively and non-invasively.

The proportional contributions of growth and metabolism to ${ }^{15} \mathrm{~N}$ turnover rates were calculated from Models $\mathrm{C}$ to $\mathrm{E}$. In the best-fitting models according to $\triangle \mathrm{AICc}$, growth was the predominant contributor to ${ }^{15} \mathrm{~N}$ turnover for muscle, fin and scale tissue, accounting for 58, 63 and 100\% of isotopic change, respectively. In comparison, Hesslein et al., (1993) determined that in juvenile broad whitefish Coregonus nasus (Pallas, 1776), 90\% of the observed isotopic changes that occurred following a diet shift was due to growth. This strong influence of growth on isotopic turnover has also been reported for ectothermic animals more generally (e.g. MacAvoy et al., 2001; Perga \& Gerdeaux, 2005; Heady \& Moore, 2013) and is attributed to them having lower metabolic activities than endotherms (Bosley et al., 2002; Tominaga et al., 2003). Indeed, Perga and Gerdeaux (2005) suggested that as fish, and other ectotherms, have a discontinuous pattern of growth over the year, the stable isotope values of their muscle might only reflect their food consumed during periods of growth. In studies where the turnover of multiple tissues have been compared, isotopic turnover rates vary substantially according to their relative metabolic activity (e.g. McIntyre \& Flecker, 2006; Carleton \& Del Rio, 2010), with elevated turnover rates in metabolically active tissues (Herzka \& Holt, 2000; Gaye-Siessegger et al., 2004).

This relative importance of growth to turnover rates of fishes is also important in the context of the growth rates of the experimental fish, where increments were relatively low (mean $0.17 \mathrm{~mm} \mathrm{~d}^{-1}$ ) when compared to those achieved by $B$. barbus in some wild populations (e.g. $0.40 \mathrm{~mm} \mathrm{~d}^{-1}$; Britton et al., 2013). This slow growth rate in the experiment was likely to relate to their husbandry in aquaria conditions that included their feeding upon on a formulated feed of relatively low protein content. This slow growth was likely to have been a major determinant of the relatively slow isotopic turnover rates detected in all fish tissues; had their husbandry conditions facilitated a faster growth rate then elevated turnover rates could have resulted. Moreover, the initial stable isotope data were not collected until Day 50 and thus some more important detail on isotopic change in the period immediately after the diet-switch could have been missed. Correspondingly, extrapolating isotopic half-life estimates and the $95 \%$ turnover rates produced in ex situ conditions to wild fish, particularly larger, adult fish, might need some caution, as they are likely to have resulted in some over-estimates and so the generated values are likely to represent maximum values, rather than optimal ones. It is recommended that some refinement via further experimentation is needed to determine how turnover varies with growth rate and diet composition. This would be coupled with more regular sampling early in the experimental period to identify the initial rates of isotopic change. In addition, the size of the scales of the experimental fishes were 
relatively small, thus they tended to be used whole and thus their relatively long turnover rate might relate to their use in this manner that resulted in some aspects of their former diets influencing their isotopic data. When scales from larger, wild fish are used then it is recommended that only material collected the edge of the scale is used as it represents the most recent growth (cf. Bašić \& Britton, 2016; Gutmann Roberts et al., 2017).

When ex situ experiments determine turnover rates, they also tend to utilise the juvenile life-stages of the model species. This also raises some caution as to the applicability of these predictions to older life-stages, where individuals are likely to be slower growing and sexually mature (Hesslein et al., 1993; Herzka \& Holt, 2000; Perga \& Gerdeaux, 2005). Where experimental studies have been completed on larger or older fishes, and those with lower specific growth rates, the results suggest that metabolic replacement contributes a major proportion of total turnover, in some cases accounting for $80 \%$ of isotopic change in dorsal muscle (Suzuki et al., 2005; Logan et al., 2006; Tarboush et al., 2006). Heady and Moore (2013) revealed that catabolism contributed more to ${ }^{15} \mathrm{~N}$ turnover in tissues with faster turnover rates, contributing $68 \%$ for fin compared to $0.7 \%$ for scales. Experimental design, especially the temperature used, can also significantly impact turnover rates, with higher water temperatures reducing the half-lives of the carbon stable isotope of muscle in similar sized fish (Bosley et al., 2002; Witting et al., 2004). Caution must also be applied when the contributions of metabolism to turnover are estimated and represented by a metabolic constant, as this constant covers all non-growth processes that contribute to turnover, including inter-tissue recycling of nutrients, preferential isotopic routing and amino-acid effects, and these processes may operate differently during isotopic uptake and elimination (MacNeil et al., 2006). As there has been limited analysis of the relative fates of ${ }^{15} \mathrm{~N}$ in turnover in fishes then knowledge on its mechanistic basis remains scarce.

The experiment here on three tissues of B. barbus thus revealed there was considerable variation in their turnover rates. The results contribute to a growing body of evidence that suggest stable isotope turnover is faster in tissues with higher metabolic activity and within muscle, fin and scale tissue, growth is the dominant contributor to isotopic change.
Nevertheless, contribution from metabolism should not be disregarded or underestimated, particularly in muscle tissue. The results highlight that whilst understandings on the mechanistic basis of isotopic turnover remains relatively limited, the use of turnover estimates, as either a function of time or body mass, should be incorporated into the design of ecological studies based on stable isotopes wherever possible. This is particularly important for isotope ecology studies where the non-destructive use of tissues such as fins and scales is being used in preference to dorsal muscle, as the results here suggest their turnover rates might differ considerably, albeit with these estimates derived from fish with relatively slow growth rates. Whilst some caution needs to be applied when applying experimental data from juvenile fish to field data from larger, older fishes, these results nevertheless stress the importance of ecological researchers having greater understandings of the role of time and growth in their isotopic data.

Acknowledgements We thank two anonymous reviewers for their constructive comments to improve the paper during reviews.

Open Access This article is distributed under the terms of the Creative Commons Attribution 4.0 International License (http:// creativecommons.org/licenses/by/4.0/), which permits unrestricted use, distribution, and reproduction in any medium, provided you give appropriate credit to the original author(s) and the source, provide a link to the Creative Commons license, and indicate if changes were made.

\section{References}

Bašić, T. \& J. R. Britton, 2016. Characterizing the trophic niches of stocked and resident cyprinid fishes: consistency in partitioning over time, space and body sizes. Ecology and Evolution 6: 5093-5104.

Bearhop, S., S. Waldron, S. C. Votier \& R. W. Furness, 2002. Factors that influence assimilation rates and fractionation of nitrogen and carbon stable isotopes in avian blood and feathers. Physiological and Biochemical Zoology 75: 451-458.

Boecklen, W. J., C. T. Yarnes, B. A. Cook \& A. C. James, 2011. On the use of stable isotopes in trophic ecology. Annual Reviews in Ecology, Evolution and Systematics 42: 411-440.

Bosley, K. L., D. A. Witting, R. C. Chambers \& S. C. Wainright, 2002. Estimating turnover rates of carbon and nitrogen in recently metamorphosed winter flounder Pseudopleuronectes americanus with stable isotopes. Marine Ecology Progress Series 236: 233-240. 
Britton, J. R. \& J. Pegg, 2011. Ecology of European barbel Barbus barbus: implications for river, fishery, and conservation management. Reviews in Fisheries Science 19: 321-330.

Britton, J. R., G. D. Davies \& J. Pegg, 2013. Spatial variation in the somatic growth rates of European barbel Barbus barbus: a UK perspective. Ecology of Freshwater Fish 22: 21-29.

Buchheister, A. \& R. J. Latour, 2010. Turnover and fractionation of carbon and nitrogen stable isotopes in tissues of a migratory coastal predator, summer flounder (Paralichthys dentatus). Canadian Journal of Fisheries and Aquatic Sciences 67: 445-461.

Burnham, K. P. \& D. R. Anderson, 2002. Model selection and multimodel inference: a practical information-theoretic approach, (2nd edition). Springer-Verlag, New York.

Busst, G., T. Bašić \& J. R. Britton, 2015. Stable isotope signatures and trophic-step fractionation factors of fish tissues collected as non-lethal surrogates of dorsal muscle. Rapid Communications in Mass Spectrometry 29: 1535-1544.

Busst, G. M. \& J. R. Britton, 2016. High variability in stable isotope diet - tissue discrimination factors of two omnivorous freshwater fishes in controlled ex situ conditions. Journal of Experimental Biology 219: 1060-1068.

Carleton, S. A. \& C. M. Del Rio, 2010. Growth and catabolism in isotopic incorporation: a new formulation and experimental data. Functional Ecology 24: 805-812.

Church, M. R., J. L. Ebersole, K. M. Rensmeyer, R. B. Couture, F. T. Barrows \& D. L. Noakes, 2009. Mucus: a new tissue fraction for rapid determination of fish diet switching using stable isotope analysis. Canadian Journal of Fisheries and Aquatic Sciences 66: 1-5.

Fry, B. \& C. Arnold, 1982. Rapid ${ }^{13} \mathrm{C} /{ }^{12} \mathrm{C}$ turnover during growth of brown shrimp (Penaeus aztecus). Oecologia 54: 200-204.

Gaye-Siessegger, J., U. Focken, S. Muetzel, H. Abel \& K. Becker, 2004. Feeding level and individual metabolic rate affect $\delta^{13} \mathrm{C}$ and $\delta^{15} \mathrm{~N}$ values in carp: implications for food web studies. Oecologia 138: 175-183.

Gutmann Roberts, C., T. Bašić, F. Amat Trigo \& J. R. Britton, 2017. Trophic consequences for riverine cyprinid fishes of angler subsidies based on marine-derived nutrients. Freshwater Biology. doi:10.1111/fwb.12910.

Hayden, B., D. X. Soto, T. D. Jardine, B. S. Graham, R. A. Cunjak, A. Romakkaniemi \& T. Linnansaari, 2015. Small tails tell tall tales - intra-individual variation in the stable isotope values of fish fin. PloS One 10: e0145154.

Heady, W. N. \& J. W. Moore, 2013. Tissue turnover and stable isotope clocks to quantify resource shifts in anadromous rainbow trout. Oecologia 172: 21-34.

Hertz, E., M. Trudel, R. D. Brodeur, E. A. Daly, L. Eisner, E. V. Farley Jr., J. A. Harding, R. B. MacFarlane, S. Mazumder, J. H. Moss \& J. M. Murphy, 2015. Continentalscale variability in the feeding ecology of juvenile Chinook salmon along the coastal Northeast Pacific Ocean. Marine Ecology Progress Series 537: 247-263.

Herzka, S. Z. \& G. J. Holt, 2000. Changes in isotopic composition of red drum (Sciaenops ocellatus) larvae in response to dietary shifts: potential applications to settlement studies. Canadian Journal of Fisheries and Aquatic Sciences 57: 137-147.
Hesslein, R. H., K. A. Hallard \& P. Ramlal, 1993. Replacement of sulfur, carbon, and nitrogen in tissue of growing broad whitefish (Coregonus nasus) in response to a change in diet traced by $\delta^{34} \mathrm{~S}, \delta^{13} \mathrm{C}$, and $\delta^{15} \mathrm{~N}$. Canadian Journal of Fisheries and Aquatic Sciences 50: 2071-2076.

Hobson, K. A. \& R. G. Clark, 1992. Assessing avian diets using stable isotopes I: turnover of ${ }^{13} \mathrm{C}$ in tissues. Condor 94 : 181-188.

Jackson, M. C., R. Allen, J. Pegg \& J. R. Britton, 2013. Do trophic subsidies affect the outcome of introductions of a non-native freshwater fish? Freshwater Biology 58: 2144-2153.

Logan, J., H. Haas, L. Deegan \& E. Gaines, 2006. Turnover rates of nitrogen stable isotopes in the salt marsh mummichog, Fundulus heteroclitus, following a laboratory diet switch. Oecologia 147: 391-395.

MacAvoy, S. E., S. A. Macko \& G. C. Garman, 2001. Isotopic turnover in aquatic predators: quantifying the exploitation of migratory prey. Canadian Journal of Fisheries and Aquatic Sciences 58: 923-932.

MacNeil, M. A., K. G. Drouillard \& A. T. Fisk, 2006. Variable uptake and elimination of stable nitrogen isotopes between tissues in fish. Canadian Journal of Fisheries and Aquatic Sciences 63: 345-353.

McIntyre, P. B. \& A. S. Flecker, 2006. Rapid turnover of tissue nitrogen of primary consumers in tropical freshwaters. Oecologia 148: 12-21.

Matley, J. K., A. T. Fisk, A. J. Tobin, M. R. Heupel \& C. A. Simpfendorfer, 2016. Diet-tissue discrimination factors and turnover of carbon and nitrogen stable isotopes in tissues of an adult predatory coral reef fish, Plectropomus leopardus. Rapid Communications in Mass Spectrometry 30: $29-44$.

Mazerolle, M. J. 2016. AICcmodavg: Model Selection and Multimodel Inference Based on (Q)AIC(c). R package version 2.1-0. https://cran.r-project.org/package= AICcmodavg. Last accessed 15/05/2017.

Perga, M. E. \& D. Gerdeaux, 2005. 'Are fish what they eat' all year round? Oecologia 144: 598-606.

R Core Team, 2014. R: a Language and Environment for Statistical Computing. R Foundation for Statistical Computing, Vienna. http://www.R-project.org/.

Sun, H., K. Lü, E. J. Minter, Y. Chen, Z. Yang \& D. J. Montagnes, 2012. Combined effects of ammonia and microcystin on survival, growth, antioxidant responses, and lipid peroxidation of bighead carp Hypophthalmythys nobilis larvae. Journal of Hazardous Materials 221: 213-219.

Suzuki, K. W., A. Kasai, K. Nakayama \& M. Tanaka, 2005. Differential isotopic enrichment and half-life among tissues in Japanese temperate bass (Lateolabrax japonicus) juveniles: implications for analyzing migration. Canadian Journal of Fisheries and Aquatic Sciences 62: 671-678.

Sweeting, C. J., S. Jennings \& N. V. C. Polunin, 2005. Variance in isotopic signatures as a descriptor of tissue turnover and degree of omnivory. Functional Ecology 19: 777-784.

Tarboush, R. A., S. E. MacAvoy, S. A. Macko \& V. Connaughton, 2006. Contribution of catabolic tissue replacement to the turnover of stable isotopes in Danio rerio. Canadian Journal of Zoology 84: 1453-1460. 
Thomas, S. M. \& T. W. Crowther, 2015. Predicting rates of isotopic turnover across the animal kingdom: a synthesis of existing data. Journal of Animal Ecology 84: 861-870.

Tieszen, L. L., T. W. Boutton, K. G. Tesdahl \& N. A. Slade, 1983. Fractionation and turnover of stable carbon isotopes in animal tissues: implications for $\delta^{13} \mathrm{C}$ analysis of diet. Oecologia 57: 32-37.

Tominaga, O., N. Uno \& T. Seikai, 2003. Influence of diet shift from formulated feed to live mysids on the carbon and nitrogen stable isotope ratio $\left(\delta^{13} \mathrm{C}\right.$ and $\left.\delta^{15} \mathrm{~N}\right)$ in dorsal muscles of juvenile Japanese flounders, Paralichthys olivaceus. Aquaculture 218: 265-276.

Tran, T. N. Q., M. C. Jackson, D. Sheath, H. Verreycken \& J. R. Britton, 2015. Patterns of trophic niche divergence between invasive and native fishes in wild communities are predictable from mesocosm studies. Journal of Animal Ecology 84: 1071-1080.

Vašek, M., L. Vejřík, I. Vejř́iková, M. Šmejkal, R. Baran, M. Muška, J. Kubečka \& J. Peterka, 2017. Development of non-lethal monitoring of stable isotopes in asp (Leuciscus aspius): a comparison of muscle, fin and scale tissues. Hydrobiologia 785: 327-335.

Vander Zanden, M. J., M. K. Clayton, E. K. Moody, C. T. Solomon \& B. C. Weidel, 2015. Stable isotope turnover and half-life in animal tissues: a literature synthesis. PLoS One 10: e0116182.

Witting, D. A., R. C. Chambers, K. L. Bosley \& S. C. Wainright, 2004. Experimental evaluation of ontogenetic diet transitions in summer flounder (Paralichthys dentatus), using stable isotopes as diet tracers. Canadian Journal of Fisheries and Aquatic Sciences 61: 2069-2084.

Xia, B., Q. F. Gao, S. L. Dong \& F. Wang, 2013a. Carbon stable isotope turnover and fractionation in grass carp Ctenopharyngodon idella tissues. Aquatic Biology 19: 207-216.

Xia, B., Q. F. Gao, S. L. Dong \& F. Wang, 2013b. Turnover and fractionation of nitrogen stable isotope in tissues of grass carp Ctenopharyngodon idellus. Aquaculture Environment Interactions 3: 177-186. 